\title{
IMPACT TEST ON GEOPOLYMER CONCRETE SLABS
}

\author{
T Kiran', Sadath Ali Khan Zai ${ }^{2}$, Srikant Reddy $\mathbf{S}^{3}$ \\ ${ }^{1}$ Associate Professor, Civil Engineering Department, UVCE, Bangalore, Karnataka, India \\ ${ }^{2}$ Associate Professor, Civil Engineering Department, UVCE, Bangalore, Karnataka, India \\ ${ }^{3} P G$ Student, Civil Engineering Department, UVCE, Bangalore, Karnataka, India
}

\begin{abstract}
Geopolymer is an eco-friendly binding material alternative for Ordinary Portland Cement (OPC). Geopolymer concrete is produced by mixing fly ash, GGBS, alkaline solution, fine aggregate and coarse aggregate. Alkaline solution is composed of $\mathrm{NaOH}$ and $\mathrm{Na}_{2} \mathrm{SiO}_{3}$ solution. This paper deals with the study of impact resistance capacity of geopolymer concrete slabs subjected to impact loading. For this study, ten specimens of size $600 \mathrm{~mm}$ (length) $\times 600 \mathrm{~mm}$ (width) $\times 60 \mathrm{~mm}$ (thick) were casted with nine different combination of geopolymer concrete mix using different molar sodium hydroxide solutions and different percentages of mineral admixtures and a normal concrete slab as control slab. The molarity of NaOH solution used was $8 M$, 12M and 16M. Fly ash and GGBS admixtures were used in three different ratios of 100:0, 75:25 and 50:50.The slabs were oven cured at $60^{\circ} \mathrm{C}$ for 24 hours. These slabs were subjected to impact loading by drop weight test method. All the slabs were tested under a drop weight of $75.50 \mathrm{~N}$ through a guide pipe from a height of $700 \mathrm{~mm}$. The results obtained from this study showed that with the increase in molarity of $\mathrm{NaOH}$ solution, the strength characteristics and the impact resistance capacity of the specimen increases. Also increase in percentage of GGBS content as replacement for Fly ash content increases the impact resistance and overall strength characteristics of geopolymer concrete. From the test results, geopolymer concrete slab with $16 \mathrm{M} \mathrm{NaOH}$ solution using 50:50 Fly ash and GGBS content showed higher impact energy absorption capacity as compared other geopolymer mixes.
\end{abstract}

Key Words: Geopolymer, Molarity, Impact loading, First crack, Ultimate failure etc...

\section{INTRODUCTION}

In 1978, Joseph Davidovits initiated inorganic polymeric material that can be used to react with another source material to form a binder. The application of this binder is recently being focused to replace Ordinary Portland Cement (OPC) portion in concrete. Employment of waste material like fly ash, GGBS, and other cement replacement material (CRM) can only replace cement portion until certain percentage. But in Geopolymer concrete, all cement portions of concrete can be replaced completely using some mineral admixtures as the main binder. Geopolymer concrete consists of alkaline liquid and source material. Usually a combination of $\mathrm{NaOH}$ or $\mathrm{KOH}$ with $\mathrm{Na}_{2} \mathrm{SiO}_{3}$ or $\mathrm{K}_{2} \mathrm{SiO}_{3}$ is used as Alkaline liquid. The addition of $\mathrm{Na}_{2} \mathrm{SiO}_{3}$ solution to $\mathrm{NaOH}$ solution will enhance the reaction rate between alkaline liquid and source material. Their mechanical properties are influenced by factors including raw materials, alkaline to fly ash ratio, activator type and curing conditions. These alkaline liquids are generally used depending upon the molarity of $\mathrm{NaOH}$ solution such as $8 \mathrm{M}, 10 \mathrm{M}, 12 \mathrm{M}$, $14 \mathrm{M}, 16 \mathrm{M}$ etc.

High loading rate and very short period of contact that cause high strain rate in the structure are the characteristics of the impact load. The behaviour of all materials and structural elements will be different under impact load when compared with static loads. Due to the complex nature of dynamic loading on concrete structures, use of the traditional methods of analysis and design may not give the expected results under impact loading. Hence various researchers in the past few years carried out investigations to understand the response of impact loading on concrete and concrete based composites.

\section{LITERATURE REVIEW}

Madheswaran C. K et al. (2014) ${ }^{1}$ investigated on behaviour of reinforced geopolymer concrete slab under repeated low velocity impact loading. Ordinary Portland cement concrete and Geopolymer concrete slabs of size 1000 × 1000 × $60 \mathrm{~mm}$ were casted to study its behaviour under impact loading. The slabs were mounted on a supporting frame with hinged support conditions. A hammer of mass $8.4 \mathrm{~kg}$ is used for impact test. A dynamic load cell is connected to the tape recorder through a strain gauge conditioner and an amplifier. This is used for measuring impact and pulsating forces. Free fall of impact at the centre of slab simulates impact load. TEAC Instrumentation tape recorder is used to record the impact load, strain and acceleration signals for every drop. From the test results, it is found that GPC slabs performed better when compared to OPCC slabs at initial cracking and failure stages of slabs under impact test. The plain slabs failed by perforation while fibre reinforced slabs failed by scabbing. There is progressive degradation of concrete stiffness under low energy repeated impact loading..

In the experimental work carried out by S. Nagan and R.Mohana (2014) ${ }^{2}$, they found the resistance of geopolymer mortar slabs under impact load by dropping a steel ball from a considerable height. For this study, they used specimens of size $230 \times 230 \times 25 \mathrm{~mm}$ with different combinations of chicken mesh and rectangular weld mesh and are subjected 
to impact load by drop weight test and the impact energy required for first crack and final crack were calculated. They found that the combination of chicken mesh and rectangular weld mesh together showed better performance in case of energy absorption and residual impact strength. The compressive strength, flexural strength and split tensile strength of $10 \mathrm{M}$ geopolymer mortar specimens are found to be $36.05 \%, 33 \%$ and $27.7 \%$ more when compared to cement mortar specimens respectively. Also with increase in volume of reinforcement, energy absorption of geopolymer ferrocement specimen increases compared to cement mortar specimen.

In this experimental investigation, Dr. Abdulkader Ismail Al-Hadithi et al. $(\mathbf{2 0 1 4})^{3}$ studied the behaviour of ferrocement slabs under impact load by varying the parameters like number of layers of meshes, SBR polymer content and height of fall. For this study, they used specimens of size $500 \times 500 \times 50 \mathrm{~mm}$ and weight of fall is about $1.3 \mathrm{~kg}$ and the height of fall is $2.5 \mathrm{~m}, 1.2 \mathrm{~m}$ and $0.83 \mathrm{~m}$. The specimens were casted and tested at an age of 56 days and the no. of blows required for first and final crack were recorded. The impact resistance capacity of the specimens was calculated. They concluded that, the impact energy absorption capacity of the ferrocement specimen increases as the polymer content percentage and the number of layers of wire mesh increases.

Madheswaran C. K et al. (2013) ${ }^{4}$ studied the effect of molarity in geopolymer concrete. Different molarities of $\mathrm{NaOH}$ solution $(3 \mathrm{M}, 5 \mathrm{M}$ and $7 \mathrm{M})$ are taken to prepare different mixtures of GPC slabs. The test specimens of 150 $\mathrm{mm}$ cubes, $150 \times 300 \mathrm{~mm}$ cylinders were prepared and cured at ambient temperature conditions. The GPC specimens are tested for their compression strength at the age of 7 and 28 days. Based on the experimental investigations, it was concluded that the compressive strength of the geopolymer concrete is increased with the increasing concentration of $\mathrm{NaOH}$. It has been observed that the increasing the quantity of GGBS and Compressive strength of geopolymer increases.

\section{RESEARCH SIGNIFICANCE}

In this investigation, the experiments were conducted to understand the structural behavior of GPC slabs under impact loading. The tests were mainly focused on the impact load test of reinforced GPC slabs with all the four edges in fixed condition by drop weight test. This paper presents the no. of blows required for first crack stage, ultimate stage, impact load and energy absorption at first crack and ultimate stage.

\section{MATERIALS}

\subsection{Fly Ash}

Fly ash is the most abundantly used mineral admixture as replacement for cement in concrete. It is also the main ingredient for geopolymer concrete due to its active participation in the geopolymerization process. Pozzolanic material exhibits cementitious properties when combined with calcium hydroxide. Fly ash is used as the pozzolana in many concrete applications. Fly ash From Bellary ZINDAL steel plant, Karnataka is used as cement replacement material in this investigation.

\subsection{Ground Granulated Blast Furnace Slag}

Ground granulated blast furnace slag comprises mainly of calcium oxide, silicon di-oxide, aluminium oxide, magnesium oxide. It has the same chemical constituents as OPC but in different proportions. And the addition of GGBS in Geo-Polymer Concrete increases the strength of the concrete and also curing of Geo-Polymer concrete at room temperature is possible. Ground granulated blast furnace slag from Bellary ZINDAL steel plant, Karnataka is used as cement replacement material in this investigation which confirms to IS: 12089-1987.

\subsection{Sodium Hydroxide}

Generally $\mathrm{NaOH}$ is available in market in pellets or flakes form with $96 \%$ to $98 \%$ purity where the cost of the product depends on the purity of the material. The solution of $\mathrm{NaOH}$ was formed by dissolving it in water based on the molarity required. It is recommended that the $\mathrm{NaOH}$ solution should be made 24 hours before casting and should be used with 36 hours of mixing the pellets with water as after that it is converted to semi-solid state.

\subsection{Sodium Silicate}

It is also known as water-glass which is available in the market in gel form. The ratio of $\mathrm{SiO}_{2}$ and $\mathrm{Na}_{2} \mathrm{O}$ in sodium silicate gel highly affects the strength of geopolymer concrete. Mainly it is seen that a ratio ranging from 2 to 2.5 gives a satisfactory result. Solution was obtained from the Datta scientific in Bangalore.

\subsection{Fine Aggregate}

Locally obtained natural river sand is used as the fine aggregate in the concrete mixes. The sieve analysis result indicates that the sand confirms to zone-II as per IS: 383 1970.

\subsection{Coarse Aggregate}

Locally available crushed aggregate was been used as coarse aggregate. The aggregate passing through $12.5 \mathrm{~mm}$ IS sieve and retained on $4.75 \mathrm{~mm}$ IS sieve was used in preparation of reinforced GPC slab specimens. The tests on the coarse aggregate were conducted in accordance with IS 23861963. 


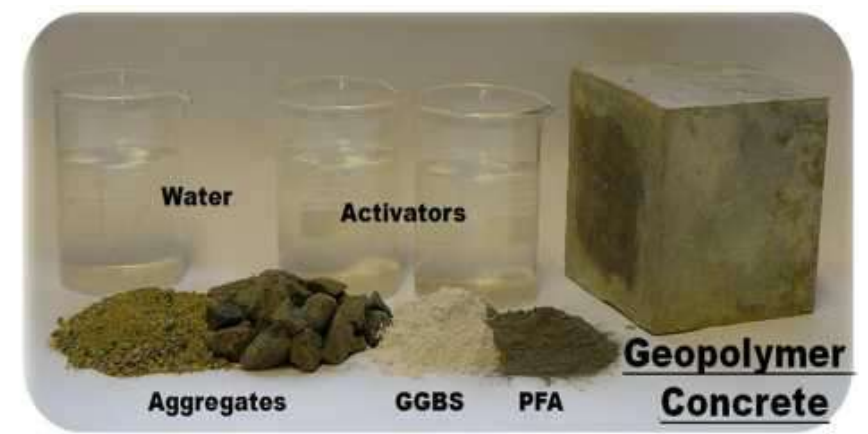

Fig -1: Constituents of Geopolymer concrete

\section{MIX PROPORTION AND EXPERIMENTAL INVESTIGATION}

\subsection{Geo-Polymer Mix Design}

Mix design samples have shown that the aggregates occupy about $75-80 \%$ by mass in Geopolymer concrete. Few assumptions are made in the mix design process as there isn't a standard mix design procedure available as per IS codes. Table below shows the mix design used here.

Table -1: Mix Proportions Value

\begin{tabular}{|c|c|}
\hline Constituents & Mix proportions $\left(\mathrm{kg} / \mathrm{m}^{3}\right)$ \\
\hline CA & 1294 \\
\hline FA & 554 \\
\hline Fly ash & 408 \\
\hline Sodium silicate & 103 \\
\hline Sodium hydroxide & 41 \\
\hline
\end{tabular}

\subsection{Preparation of Alkaline Activator Solution}

The mixture of $\mathrm{Na}_{2} \mathrm{SiO}_{3}$ solution and $\mathrm{NaOH}$ solution can be used as the alkaline liquid. The Alkali activator solution has to be prepared before 24 hours of use because at the time of mixing $\mathrm{Na}_{2} \mathrm{SiO}_{3}$ and $\mathrm{NaOH}$ solution it generates a huge amount of heat and the polymerization takes place by reacting with one another, which will act as a binder in the geopolymer concrete. It should be used within 36 hours of mixing the pellets with water as after that it is converted to semi-solid state. The Sodium hydroxide, available in small flakes, is dissolved in water at different proportions as required molarity of solution.

\subsection{Casting of test specimen}

Wooden moulds of size $600 \times 600 \times 60 \mathrm{~mm}$ clear were prepared using plywood boards. The moulds were coated initially with oil so as to enable easy removal of the moulds. The moulds were placed on an even surface. The surface was painted with waste oil. Cover blocks were used to ensure a clear cover of $10 \mathrm{~mm}$. Normal mild steel bars steel bars (nominal diameters $6 \mathrm{~mm}$ ) were used as the reinforcing material. The steel reinforcement mat with required spacing was placed inside the moulds. The moulds were supported well on all the sides from outside so as to prevent bulging of the specimen once the concrete is poured inside.
Individual materials were batched in an electronic weighing balance. Fly ash and GGBS were mixed separately. Aggregates and cementitious materials were added on to the mixer and thoroughly mixed until a uniform mix was obtained then; required quantity of alkaline solution along with water is added and mixed thoroughly to form uniform concrete mix. Moulds were filled with the concrete and compacted thoroughly.

The wooden moulds, which formed the sides of the slabs, were de-shuttered only after 48 hours to avoid development of handling stresses. The slabs were stem-cured at $60^{\circ} \mathrm{C}$ for a period of 24 hours. White wash was applied to achieve clear visibility of cracks during testing. After respective curing period the slabs were tested. Totally ten slabs were casted out of which one is reference slab and remaining nine slabs are having different molarity of $\mathrm{NaOH}$ and different percentages of Fly ash and GGBS.

The slabs are named as below:

1. CS - Conventional slab as Reference.

2. S1 - Slab with $8 \mathrm{M} \mathrm{NaOH}$ solution having $50 \%$ fly ash and $50 \%$ GGBS.

3. S2 - Slab with $8 \mathrm{M} \mathrm{NaOH}$ solution having $75 \%$ fly ash and $25 \%$ GGBS.

4. S3 - Slab with $8 \mathrm{M} \mathrm{NaOH}$ solution having $100 \%$ fly ash.

5. S4 - Slab with $12 \mathrm{M} \mathrm{NaOH}$ solution having $50 \%$ fly ash and $50 \%$ GGBS.

6. S5 - Slab with $12 \mathrm{M} \mathrm{NaOH}$ solution having $75 \%$ fly ash and $25 \%$ GGBS.

7. S6 - Slab with $12 \mathrm{M} \mathrm{NaOH}$ solution having $100 \%$ fly ash. 8. S7 - Slab with $16 \mathrm{M} \mathrm{NaOH}$ solution having $50 \%$ fly ash and $50 \%$ GGBS.

9. S8 - Slab with $16 \mathrm{M} \mathrm{NaOH}$ solution having $75 \%$ fly ash and $25 \%$ GGBS.

10. S9 - Slab with $16 \mathrm{M} \mathrm{NaOH}$ solution having $100 \%$ fly ash.

\subsection{Test Setup}

Drop weight test was used to simulate impact load on the square slabs of $600 \mathrm{~mm}$ size and test set up shown in below figure was adopted. It consists of a steel frame supported by two short columns. A steel hammer of mass $7.7 \mathrm{~kg}$ was used for impact on the specimen. The height of fall was kept as $700 \mathrm{~mm}$ and the rate of impact was 60 blows per minute. The free fall of the hammer at the centre of slab applied the impact load on the slabs. C - clamps were used to prevent the specimen from lifting up during impact.

The no. of impact blows required to develop first visible crack was used to calculate the first crack impact strength. Similarly the no. of blows required to achieve ultimate failure was used to calculate the ultimate impact strength. The schematic diagram of impact test experimental setup is shown in Figure 2. 
The energy absorption of the GPC can be calculated using the formula:

$$
E=\mathbf{N} \times(\mathbf{w} \times \mathbf{h}) \text { joules }
$$

Where,

$E$ is the energy absorbed in joules, $w$ is weight of hammer in Newton, $\mathrm{h}$ is the height of drop in meter and $\mathrm{N}$ is the no. of impact blows.

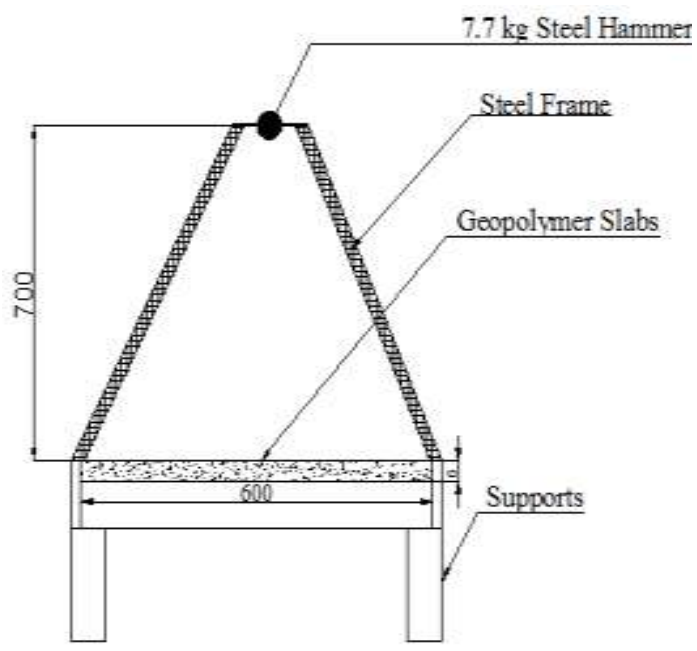

Fig -2: Schematic diagram of experimental setup

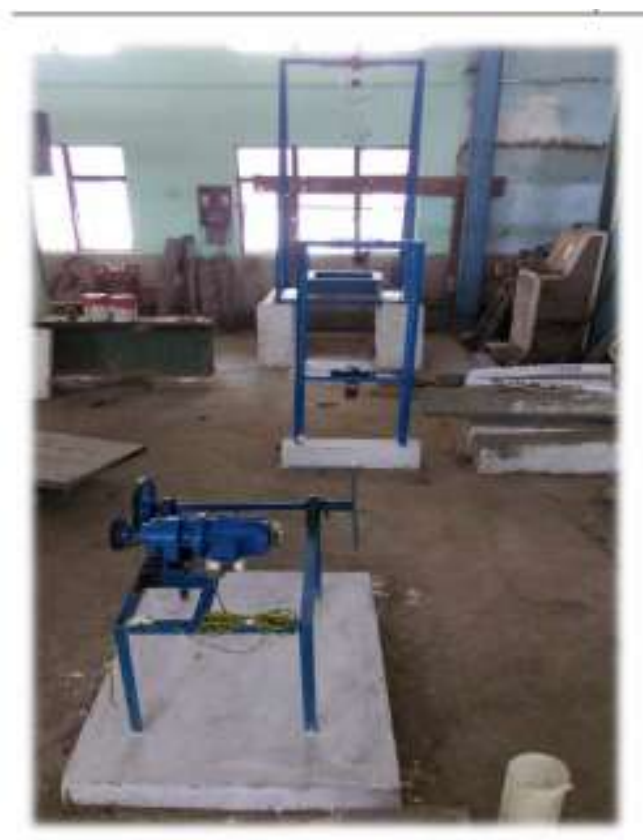

Fig -3: Experimental setup for impact loading

\section{RESULTS AND DICUSSIONS}

\subsection{Strength characteristics of GPC slabs}

The various strength tests that are to be done are listed as below.

$>$ Compressive strength

$>$ Split tensile strength

$>$ Flexural strength
The cubes of standard size $150 \mathrm{~mm}$ were tested in $2000 \mathrm{kN}$ capacity compressive testing machine as per IS: 516-1959 (1999) to get the compressive strength of GPC cubes. The prisms were tested in $100 \mathrm{kN}$ capacity impact testing machine under two point loading for specimens of $100 \mathrm{x}$ $100 \times 500 \mathrm{~mm}$ at rate of $140 \mathrm{~kg} / \mathrm{cm}^{2} /$ minute as per IS: $516-$ 1969 (1999) to get the flexural strength of concrete. The cylinders were tested in $2000 \mathrm{kN}$ capacity compressive testing machine at $1.2 \mathrm{~N} / \mathrm{cm}^{2} /$ minute to $2.4 \mathrm{~N} / \mathrm{cm}^{2} /$ minute as per IS: 516-1999 to get the split tensile strength of concrete cylinders.

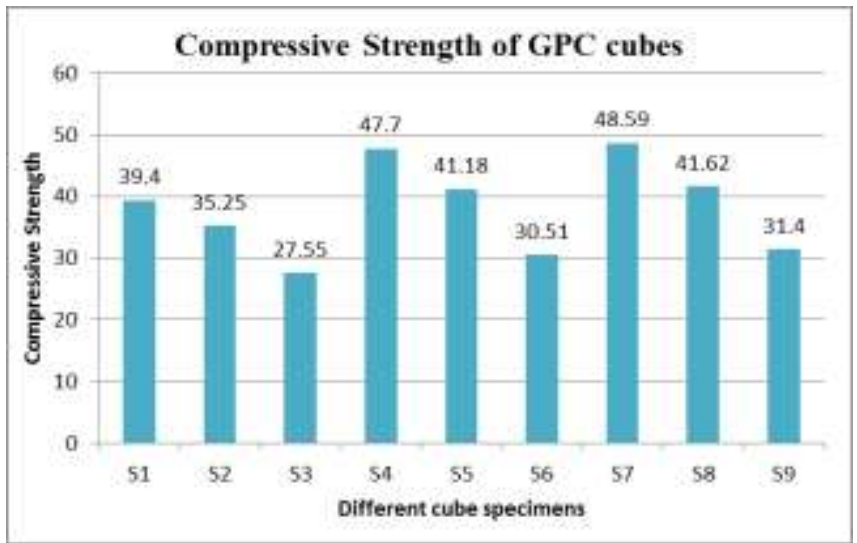

Chart -1: Compressive strength of GPC cubes

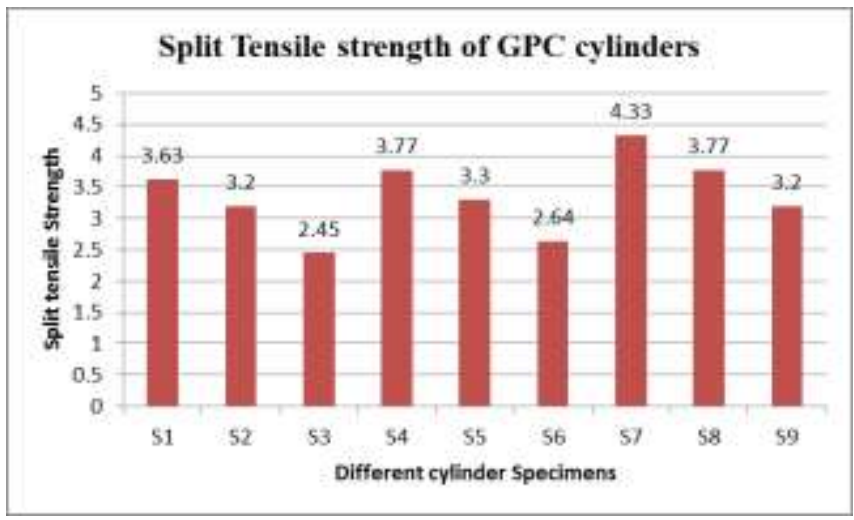

Chart -2: Split tensile strength of GPC cylinders

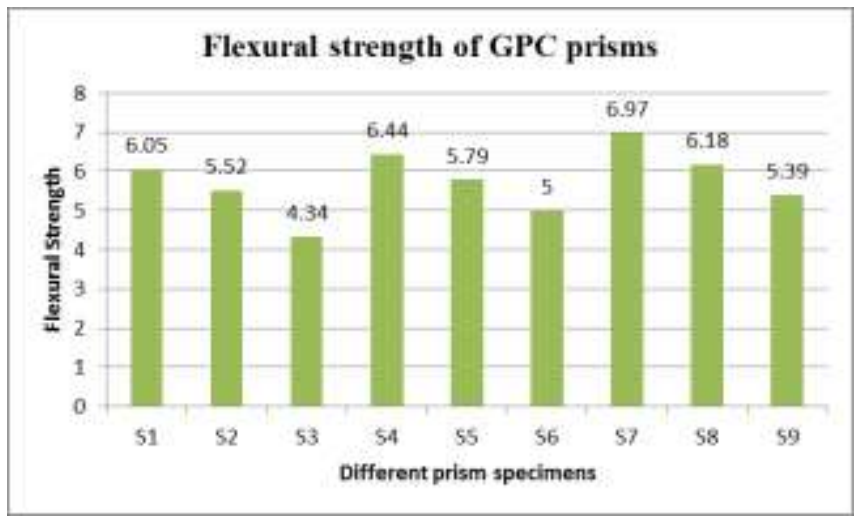

Chart 3: Flexural strength of GPC prisms

From the test results, it is observed that the compressive strength, split tensile strength and fleural strength of geopolymer concrete is slightly more than the normal M 30 
Concrete mix specimens. Also it is observed that as the molarity of $\mathrm{NaOH}$ solution used in Geopolymer concrete mix design is increased, the strength characteristics showed better results. Increase in GGBS content as replacement for fly ash showed better results and early strength.

\subsection{Energy Absorption od GPC slabs}

The test results of the normal reinforced concrete slab and GPC slabs with fly ash and GGBS as replacement for cement with steel reinforcement have been tabulated in this section. The test setup was done as explained in the earlier chapter. Initial adjustments were done before the experiment. The first crack impact strength and ultimate crack impact strength of geopolymer concrete slabs are tabulated.

Table -2: First crack impact energy of GPC slabs

\begin{tabular}{|c|c|c|}
\hline $\begin{array}{c}\text { Slab } \\
\text { Specimens }\end{array}$ & No. of blows & $\begin{array}{c}\text { First Crack Impact } \\
\text { Strength in Joules }\end{array}$ \\
\hline CS & 7 & 369.95 \\
\hline S1 & 9 & 475.65 \\
\hline S2 & 6 & 317.1 \\
\hline S3 & 4 & 211.4 \\
\hline S4 & 10 & 528.5 \\
\hline S5 & 9 & 475.65 \\
\hline S6 & 6 & 317.1 \\
\hline S7 & 12 & 634.2 \\
\hline S8 & 9 & 475.65 \\
\hline S9 & 7 & 369.95 \\
\hline
\end{tabular}

Table -3: Ultimate impact energy of GPC slabs

\begin{tabular}{|c|c|c|}
\hline $\begin{array}{c}\text { Slab } \\
\text { Specimens }\end{array}$ & No. of blows & $\begin{array}{c}\text { Ultimate Impact } \\
\text { Strength in Joules }\end{array}$ \\
\hline CS & 102 & 5390.70 \\
\hline S1 & 108 & 5707.80 \\
\hline S2 & 96 & 5073.60 \\
\hline S3 & 82 & 4333.70 \\
\hline S4 & 118 & 6236.30 \\
\hline S5 & 106 & 5602.10 \\
\hline S6 & 97 & 5126.45 \\
\hline S7 & 125 & 6606.25 \\
\hline S8 & 116 & 6130.60 \\
\hline S9 & 107 & 5654.95 \\
\hline
\end{tabular}

The energy absorption of the slab specimems is calculated based on the number of impact blows to cause failure and impact energy for each blow. Similar to strength characteristics, the impact energy absorbed by Geopolymer concrete is more than normal concrete slabs. Also the increase in molarity of $\mathrm{NaOH}$ solution in mix and increase in GGBS content as replacement for Fly ash showed increased energy absorption in the slabs. Slab specimen S7 showed the maximum strength when comapared to other mixes.

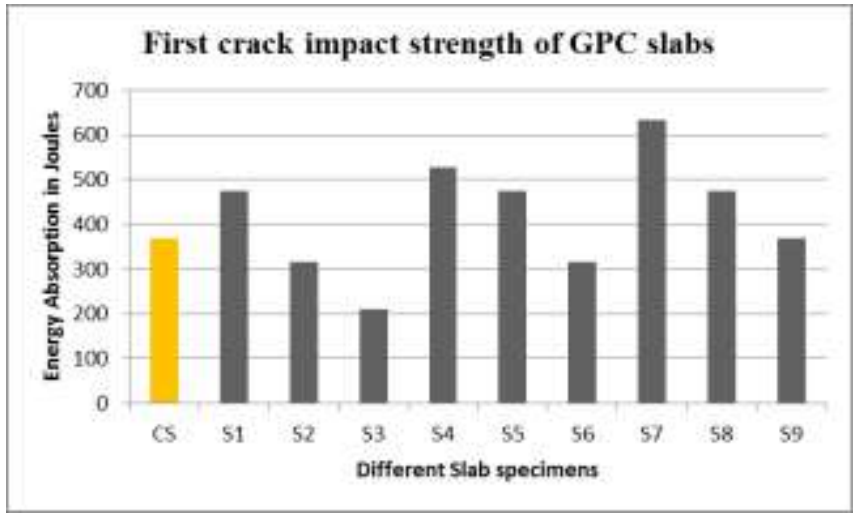

Chart -4: First crack impact strength of GPC slabs

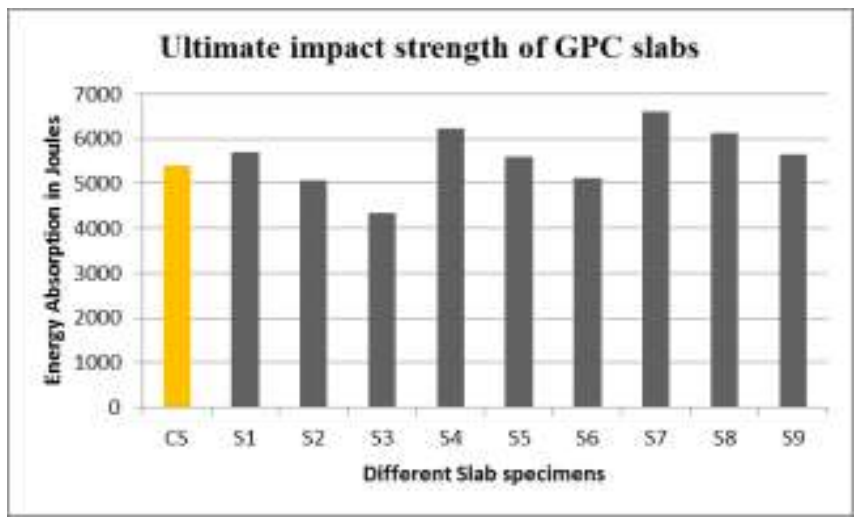

Chart -5: Ultimate impact strength of GPC slabs

\subsection{Crack pattern}

It was observed that the Geopolymer concrete specimens exhibited localized failure at the centre of slab which is the point of contact of the drop-weight impact hammer. All slab specimens failed by spalling on top face and scabbing on bottom face. The crack pattern of all the slabs was similar. The crack patterns are shown in the figure below.
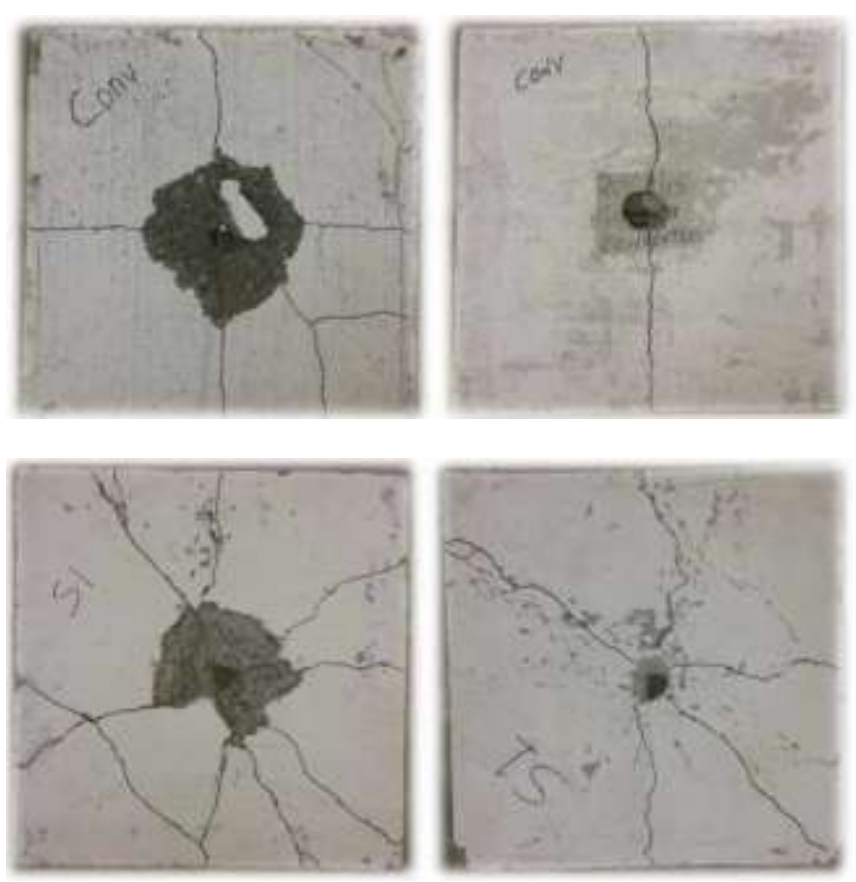

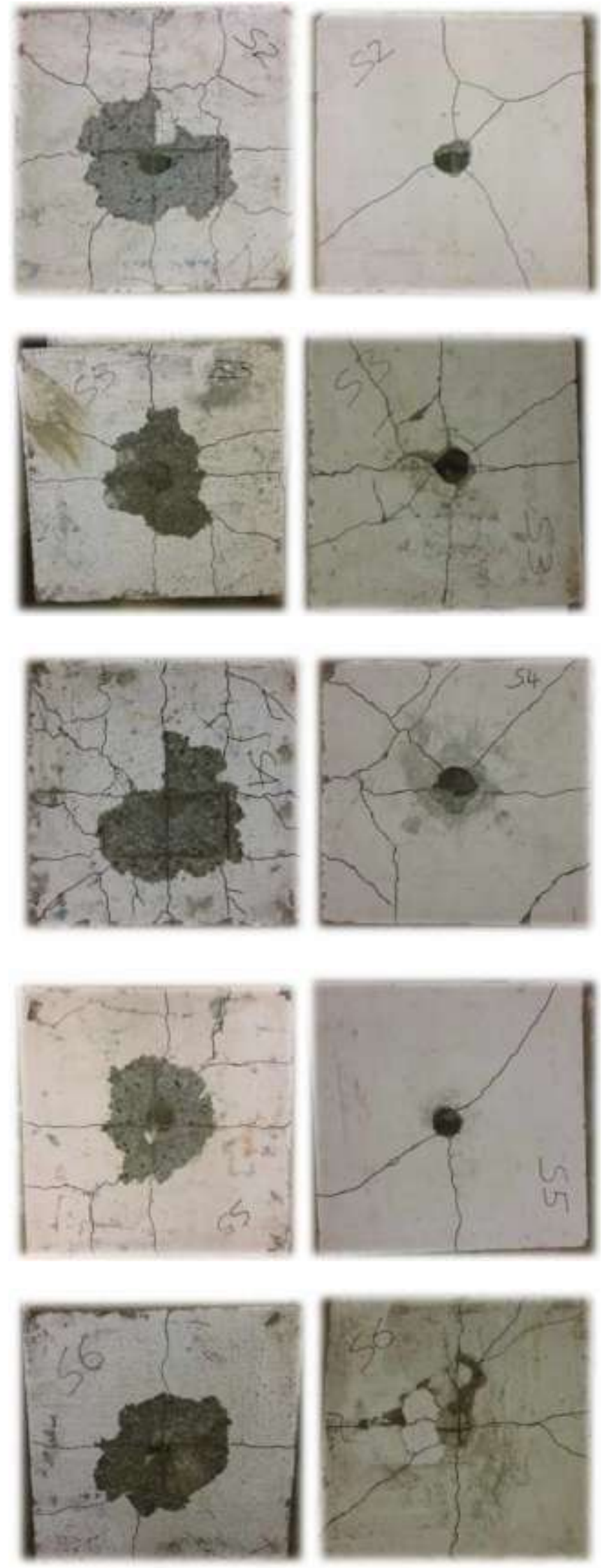
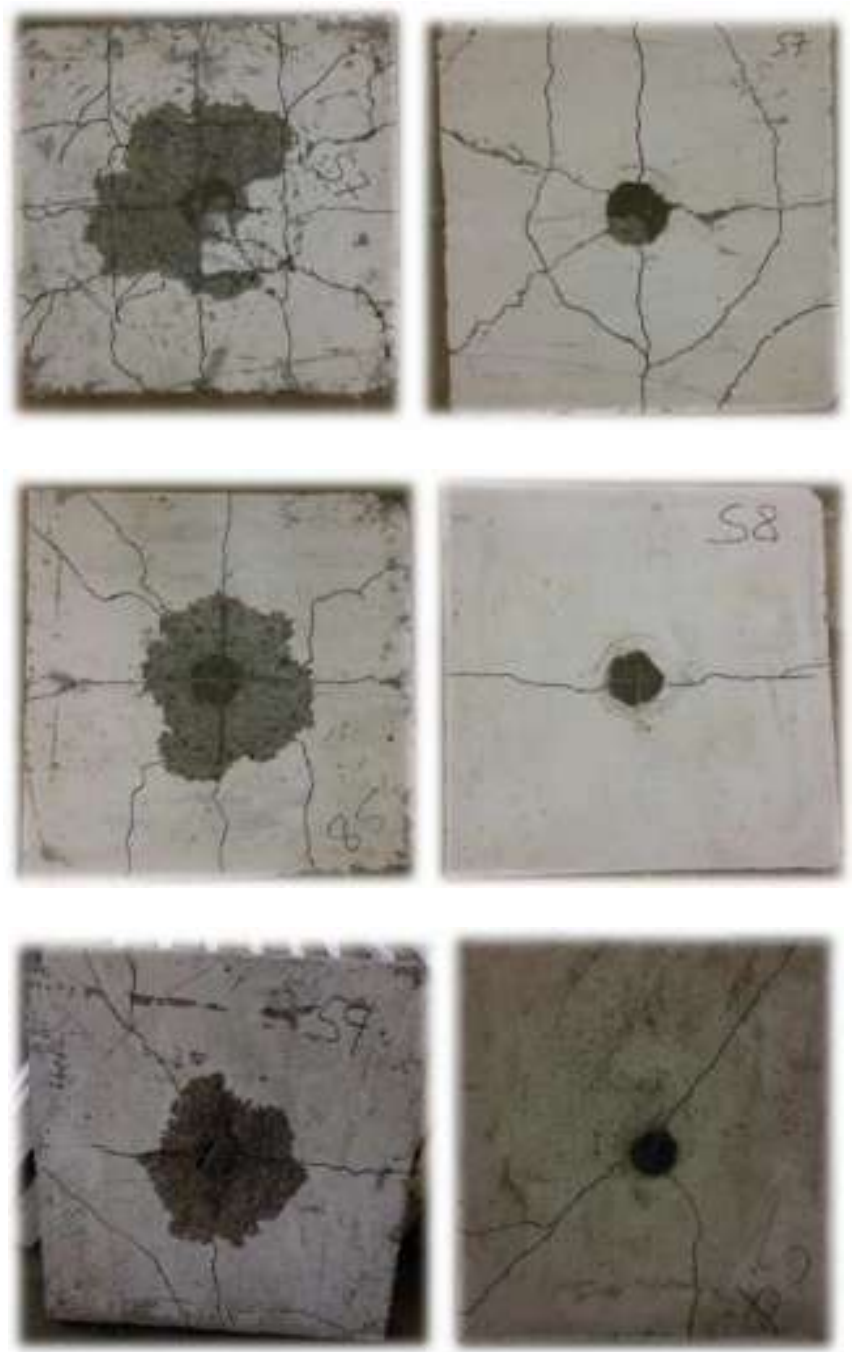

Fig -4: Crack patterns of GPC slabs Subjected to impact loading

\section{CONCLUSIONS}

- The compressive strength, split tensile strength and flexural strength of geopolymer concrete has shown marginal increase when compared to M30 normal concrete.

- The strength of GPC was found to be increased with increase in molarity of $\mathrm{NaOH}$ solution used in Geopolymer concrete mix.

- The strength of GPC increased with increase in percentage of GGBS as replacement for Fly ash in a mix.

- The energy absorption capacity of Geopolymer concrete is found to be more when compared to normal concrete.

- Increase in molarity of $\mathrm{NaOH}$ and increase in GGBS content also increases first crack impact strength and ultimate impact strength of Geopolymer concrete slabs.

- Steam curing is required and early strength can be developed. 


\section{Suggestions for Future Work}

- The experiment can be done with varying slab thickness.

- The experiment can be done with different percentages of Fly ash and GGBS.

- Different curing periods and different temperatures for geopolymer concrete can be used.

- It can be checked for chemical resistance and water absorption.

- Future study can be focused on the effect of fiber addition on the post-crack performance of geopolymer concrete.

\section{REFERENCES}

[1]. Madheswaran C K, J K Dattatreya, P S Ambily \& Karansingh P R, Investigation on behavior of reinforced geopolymer concrete slab under repeated low velocity impact loading International Journal of Innovative Research in Science, Engineering and Technology, Vol. 3, Issue 3, pp. 10775-10786, March 2014

[2]. S. Nagan and R. Mohana, Behaviour of geopolymer ferrocement Slabs subjected to impact IJST, Transactions of Civil Engineering, Vol. 38, No. C1+, pp 223-233, 2014.

[3]. Dr.Abdulkader Ismail Al-Hadithi, Dr.Khalil Ibrahim Aziz and Mohammed Tarrad Nawar Al-Dulaim, Behavior of ferro-cement slabs modified by polymer under low velocity impact Advanced Materials Research Vol. 925 (2014) pp 3-7.

[4]. Madheswaran C. K, Gnanasundar G, Gopalakrishnan. N Effect of molarity in geopolymer concrete by international journal of civil and structural engineering Volume 4, no 2, 2013. 